\title{
Hydrothermal Synthesis and Crystallographic Study of Sr-Pb Hydroxyapatite Solid Solutions
}

\author{
Kongjun ZHU, Kazumichi YANAGISAWA, ${ }^{*}$ Rie SHIMANOUCHI, ${ }^{* *}$ Ayumu ONDA, ${ }^{*}$ \\ Koji KAJIYOSHI* and Jinhao QIU \\ The Aeronautical Key Laboratory for Smart Materials and Structures, Nanjing University of Aeronautics and Astronautics, \\ Nanjing 210016, P. R. China \\ * Research Laboratory of Hydrothermal Chemistry, Faculty of Science, Kochi University, Kochi-shi 780-8520 Japan \\ ** Department of Material Science, Faculty of Science, Kochi University, Kochi-shi 780-8520 Japan
}

\begin{abstract}
A continuous series of solid solutions in the system of strontium and lead hydroxyapatite, $\mathbf{P b}_{x} \mathrm{Sr}_{1-x} \mathbf{H A P}(x=$ 0-1), was successfully synthesized by low-temperature mixing method (LTMM) at $160^{\circ} \mathrm{C}$ for $12 \mathrm{~h}$ under hydrothermal conditions. The samples were characterized by chemical analysis, electron microscopic observation and $\mathrm{X}$-ray powder-pattern fitting. The site of the metal ions in the solid solutions was analyzed by the Rietveld method. The lattice constants of the prepared solid solutions varied linearly with $\mathbf{P b}$ contents. It was found that $\mathbf{P b}^{2+}$ ions in the solid solutions preferentially occupied the $\mathbf{M}(2)$ site in the apatite structure.
\end{abstract}

[Received August 28, 2007; Accepted October 18, 2007]

Key-words : Hydroxyapatite, Solid solution, Hydrothermal synthesis, Rietveld method

1. Introduction

Calcium hydroxyapatite $\left[\mathrm{Ca}_{10}\left(\mathrm{PO}_{4}\right)_{6}(\mathrm{OH})_{2}\right.$, designated as $\mathrm{Ca} \mathrm{HAp}]$ is a primary constituent of vertebral animal's hard tissues and synthetic hydroxyapatite has attracted our attention due to its utility in the fields of bioceramics, catalyst, adsorbent, and so on. ${ }^{1)}$ Strontium hydroxyapatite $\left[\mathrm{Sr}_{10}\left(\mathrm{PO}_{4}\right)_{6}(\mathrm{OH})_{2}\right.$, designated as $\left.\mathrm{Sr} \mathrm{HAp}\right]$ has been also used as a catalyst for oxidative dehydrogenation of methane ${ }^{2)}$ and as an adsorbent for the protein. ${ }^{3)}$ In the oxidation of methane, the addition of a small quantity of lead to Sr HAp resulted in the conversion and the selectivity to ethylene. ${ }^{4)}$

In the apatite structure, the $\mathrm{Ca}$ ions occupy two types of nonequivalent sites: the $\mathrm{M}(1)$ sites are at the fourfold symmetry4(f) position and the $\mathrm{M}(2)$ sites are at the sixfold symmetry $6(\mathrm{~h})$ position. ${ }^{5)}$ The apatite structure has a high flexibility, so that many metal ions can incorporate in the structure. It is interesting to investigate the site of metal ions which incorporate in the apatite structure. Badraoui et al. ${ }^{6}$ prepared $\mathrm{Sr}-\mathrm{Pb} \mathrm{HAp}$ solid solutions from a double decomposition method, in aqueous medium. The precipitate was filtered, washed with hot distilled water, in order to eliminate traces of ammonium, nitrate and acetate ions, dried at $100^{\circ} \mathrm{C}$ for $12 \mathrm{~h}$ and calcined at $600^{\circ} \mathrm{C}$ for $4 \mathrm{~h}$ to improve its crystallinity. The results of the Rietveld analysis indicated a clear preference of lead for the $\mathbf{M}(2)$ site of the apatitic structure, so that in the samples with low $\mathrm{Pb}$ content it is almost exclusively found in the $M(2)$ site.

The HAp solid solutions have been prepared by the solid state reaction or aqueous reaction. ${ }^{7)-12}$ The former method gives higher crystallinity to the products, but the hydroxyl defect should be formed due to the high temperature treatments. On the other hand, the crystallinity of the products synthesized by the aqueous reaction is usually low even without hydroxyl defects in their structure. The low crystallinity and hydroxyl defect in the samples must cause inaccuracy in the structural investigation by the Rietveld analysis. Hydrothermal synthesis method is a wet-chemical technique for directly forming complex oxide powders with high crystallinity. ${ }^{13)}$ The technique has an advantage especially for preparation of HAp powders not to introduce the hydroxyl defect in the structure. Cd-Hap, ${ }^{14)} \mathrm{Ca}-\mathrm{Cd} \mathrm{Hap},{ }^{15), 16)} \mathrm{Ca}-\mathrm{Sr}$
Hap, ${ }^{16), 17)} \mathrm{Ca}-\mathrm{Pb} \mathrm{Hap}^{16)}$ were successfully synthesized by hydrothermal method in our former works.

In this work, we have synthesized well-formed crystals of $\mathrm{Sr}-\mathrm{Pb}$ HAp solid solution using LTMM under hydrothermal conditions at $160^{\circ} \mathrm{C}$ for $12 \mathrm{~h}$. Powder X-ray diffraction analyses were employed to determine the crystalline phases and investigate which site $\mathrm{Pb}$ ions preferentially occupy in the HAp structure by X-ray powder-pattern fitting. The obtained crystals were observed by SEM and TEM. The concentrations of $\mathrm{Sr}^{2+}, \mathrm{Pb}^{2+}$ and $\mathrm{PO}_{4}{ }^{3-}$ in the solid solutions were also measured by inductively coupled plasma (ICP) spectrometry.

\section{Experimental}

The starting materials were regent grade chemicals (Wako Pure Chem., Ind., Co., Japan), $\left(\mathrm{NH}_{4}\right)_{2} \mathrm{HPO}_{4}, \mathrm{Sr}\left(\mathrm{NO}_{3}\right)_{2}$. $4 \mathrm{H}_{2} \mathrm{O}$, and $\mathrm{Pb}\left(\mathrm{NO}_{3}\right)_{2} \cdot 4 \mathrm{H}_{2} \mathrm{O}$. $\left(\mathrm{NH}_{4}\right)_{2} \mathrm{HPO}_{4}$ was dissolved in deionized water to get a $0.200 \mathrm{~mol} \cdot \mathrm{L}^{-1}$ solution. The $\mathrm{pH}$ of the solution was adjusted to 10 with ammonia. A mixed metal nitrate solution with $0.334 \mathrm{~mol} \cdot \mathrm{L}^{-1}$ was prepared from $\mathrm{Sr}\left(\mathrm{NO}_{3}\right)_{2} \cdot 4 \mathrm{H}_{2} \mathrm{O}$ and $\mathrm{Pb}\left(\mathrm{NO}_{3}\right)_{2} \cdot 4 \mathrm{H}_{2} \mathrm{O}$ nitrates, varying the $\mathrm{Pb} /(\mathrm{Pb}+\mathrm{Sr})$ molar ratio from 0 to 1 . We used a Teflon lined multi chamber autoclave which has two separate chambers. Each starting solution $\left(8 \mathrm{~cm}^{3}\right)$ was separately poured into a different reaction chamber to get the HAp stoichiometric composition. These solutions were mixed at room temperature and then heated to desired temperature. Hydrothermal treatments were carried out at $160^{\circ} \mathrm{C}$ for $12 \mathrm{~h}$.

After washing with distilled water, the products were characterized by powder X-ray diffraction (XRD; Model RTP-300RC, Rigaku Co., Japan) with $\mathrm{Cu} \mathrm{K} \alpha$ radiation (40 $\mathrm{kV}$ and $100 \mathrm{~mA}$ ). The lattice constants were calculated by the least square method using $\mathrm{Si}$ as an internal standard. X-ray diffraction data used for the Rietveld analysis were collected by step scanning method under following conditions: $2 \theta$ range $15^{\circ}-130^{\circ}$; step width $0.02^{\circ}$; and counting time $6 \mathrm{~s}$. Rietveld analysis was performed with the program RIETAN. ${ }^{18)}$ A scanning electron microscope (SEM; Model S530, HITACHI Co., Japan) and Transmission electron microscopic (TEM; Model H-800, HITACHI Co., Japan) were used to observe their morphologies. The composition of the solid solutions was determined by using inductively coupled plasma (ICP) spec- 


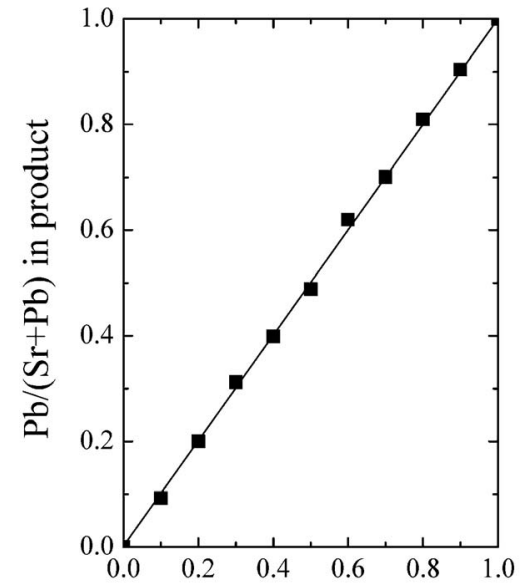

$\mathrm{Pb} /(\mathrm{Sr}+\mathrm{Pb})$ in starting solution

Fig. 1. Plot of the $\mathrm{Pb} /(\mathrm{Pb}+\mathrm{Sr})$ molar ratios in the products prepared by LTMM against that in starting solutions.

trometry (SPS7000A, Seiko) after dissolving in a nitric acid.

\section{Results and discussion}

The compositions of the products determined by the chemical analysis are shown in Fig. 1 against those of the starting solutions. $\mathrm{Pb} /(\mathrm{Sr}+\mathrm{Pb})$ molar ratio in the products is slightly higher than that of the starting solutions when it exceeds 0.6 . This indicates that $\mathrm{Pb}^{2+}$ ions more easily enter cation sites of the crystal compared to $\mathrm{Sr}^{2+}$ ions in the samples with higher $\mathrm{Pb}$ content. The $(\mathrm{Sr}+\mathrm{Pb}) / \mathrm{P}$ molar ratio of the solid solutions did not change appreciably with the change of the $\mathrm{Pb} /(\mathrm{Sr}$ $+\mathrm{Pb})$ molar ratios, and its average value of the samples obtained by LTMM was about 1.65 . The chemical compositions analyzed by ICP were used for Rietveld analysis.

The XRD patterns of the samples with the different $\mathrm{Pb} / \mathrm{Sr}$ $+\mathrm{Pb})$ molar ratio obtained by LTMM are shown in Fig. 2 . All the samples corresponded to pure apatite phase, whatever the $\mathrm{Pb} /(\mathrm{Sr}+\mathrm{Pb})$ molar ratio. The peaks shifted to lower angels with the increase of the $\mathrm{Pb} /(\mathrm{Sr}+\mathrm{Pb})$ molar ratio due to the incorporation of larger $\mathrm{Pb}^{2+}$ ions into $\mathrm{Sr} \mathrm{HAp}$. The addition of $\mathrm{Pb}^{2+}$ ions into $\mathrm{Sr} \mathrm{HAp} \mathrm{up} \mathrm{to} \mathrm{Pb} /(\mathrm{Sr}+\mathrm{Pb})$ molar ratio of 0.4 decreased the intensity of the peaks. The results preliminarily indicated that the strontium and lead hydroxyapatite solid solutions are continuous in the whole range of the $\mathrm{Pb} /(\mathrm{Sr}+\mathrm{Pb})$ molar ratio. It was also certified by the results of the lattice constant (showed in Fig. 3). The lattice constants of both $a$ and $c$ varied linearly with the compositions. It indicated that strontium and lead hydroxyapatite formed a continuous series of solid solutions. Both lead and strontium hydroxyapatite belong to the apatite structure, and both metal ions have similar ionic radius. Thus the continuous solid solutions are easily formed. The replacement of strontium by lead in the apatite structure induces a increase in the lattice constants in agreement with the bigger ionic radius of $\mathrm{Pb}^{2+}(1.33$ $\times 10^{-10} \mathrm{~m}$ for 6 -coordinate octahedral site) than that of $\mathrm{Sr}^{2+}$ $\left(1.13 \times 10^{-10} \mathrm{~m}\right.$ for 6 -coordinate octahedral site). The enlargement of $c$ axis is more than that of $a$ axis. In general, the incorporation of large ions in the columns ( $M(1)$ sites) parallel to the c-axis of the apatite structure results in a greater enlargement of the c-axis dimension than in the $\mathrm{M}(2)$ sites, because the $\mathrm{M}(1)$ sites have the shorter metal (1) -metal (1) distances in comparison with the $\mathrm{M}(2)$ sites.

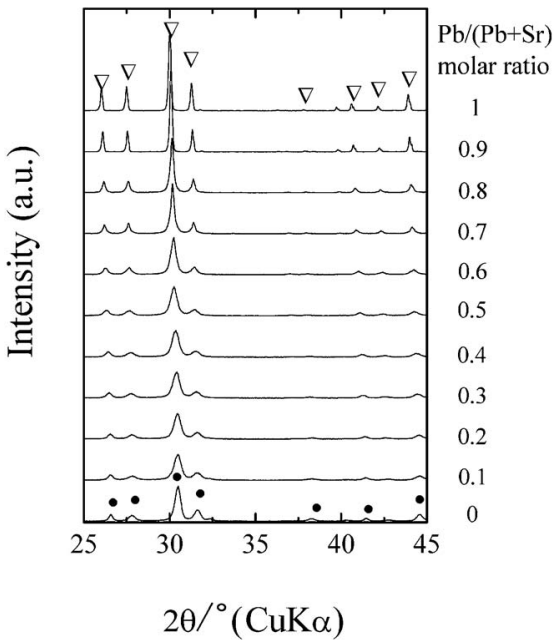

Fig. 2. X-ray diffraction patterns of the samples with different $\mathrm{Pb} /(\mathrm{Ca}+\mathrm{Pb})$ molar ratio prepared by LTMM at $160^{\circ} \mathrm{C}$ for $12 \mathrm{~h} . \nabla$ : $\mathrm{Pb}_{10}\left(\mathrm{PO}_{4}\right)_{6}(\mathrm{OH})_{2} \bullet: \mathrm{Sr}_{10}\left(\mathrm{PO}_{4}\right)_{6}(\mathrm{OH})_{2}$.

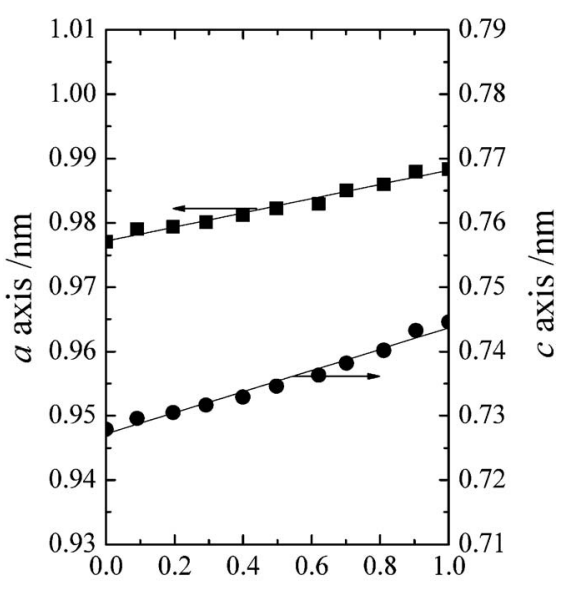

$\mathrm{Pb} /(\mathrm{Sr}+\mathrm{Pb})$ molar ratio

Fig. 3. Plot of the lattice constants of lead-strontium hydroxyapatite solid solutions prepared by LTMM against the $\mathrm{Pb} /(\mathrm{Pb}+\mathrm{Ca})$ molar ratio.

Figure 4 displays the transmission electron microscope (TEM) pictures and scanning electron microscope (SEM) photographs of the samples with different $\mathrm{Pb} /(\mathrm{Sr}+\mathrm{Pb})$ molar ratio prepared by LTMM. The morphology of the samples with less than $0.6 \mathrm{~Pb}$ content is elongated crystals, and the particle size decrease with the increase of lead content. Larger bulk crystals coexist with them in the sample with 0.8 molar ratio of $\mathrm{Pb} /(\mathrm{Sr}+\mathrm{Pb})$. The crystals of lead hydroxyapatite just are the larger bulk. The variation of the morphology is very difficult to be explained before some extra experiments are done. However, the results of the Riteveld analysis will give some explanations.

In this work, there were 11 samples prepared with LTMM, and the results of their X-ray diffraction were analyzed by the RIETAN program. The results of the $\mathrm{Pb} 50 \%$ sample obtained by LTMM showed in Table 1. The reliability factor of Rwp is acceptable for the structure determination of $\mathrm{Sr}-\mathrm{Pb}$ $\mathrm{HAp}$ in this work. Figure 5 showed the occupancy of $\mathrm{Pb}^{2+}$ in 


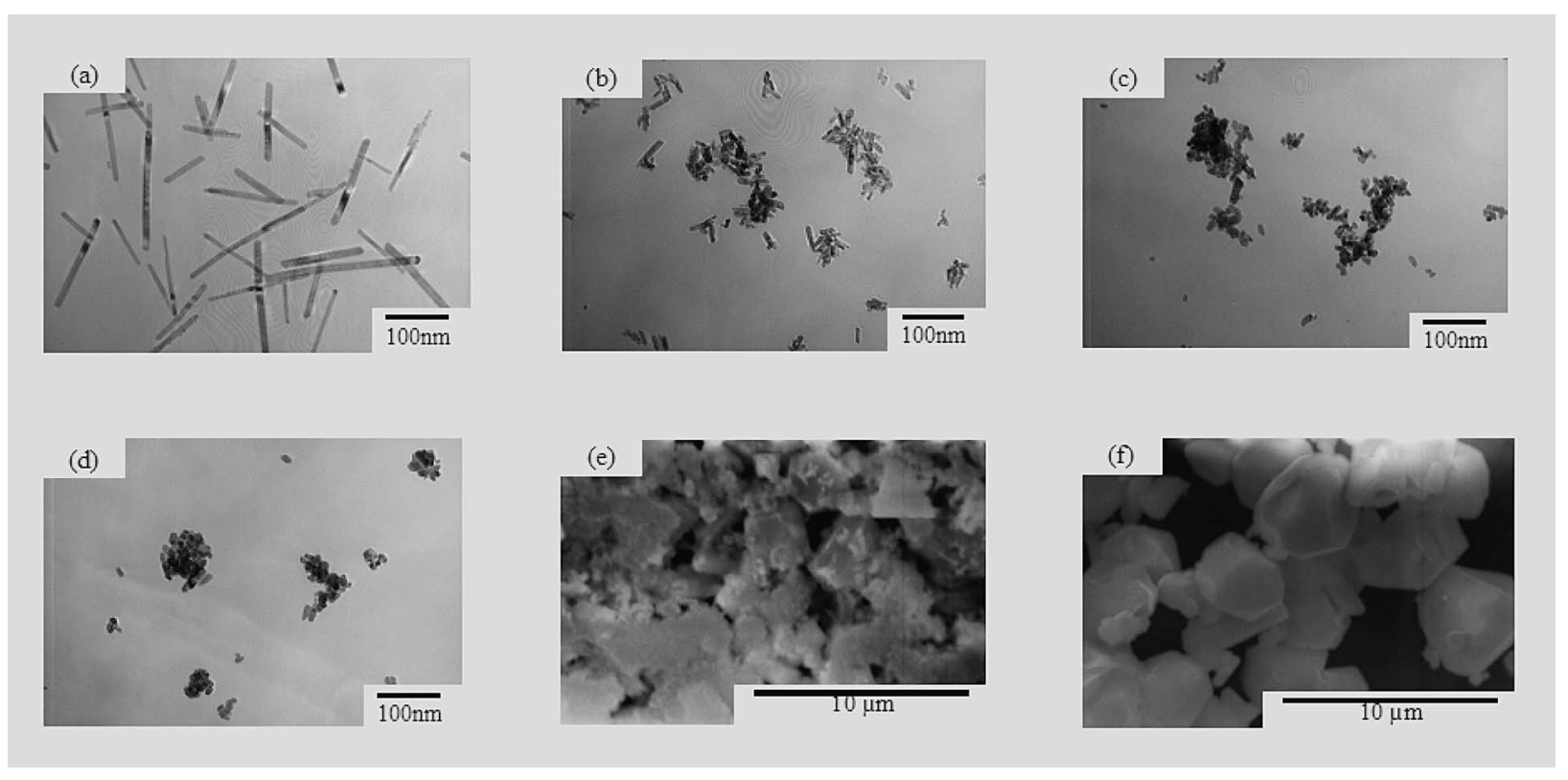

Fig. 4. TEM photographs and SEM of the samples prepared by LTMM with various $\mathrm{Pb} /(\mathrm{Pb}+\mathrm{Sr}$ ) molar ratio: (a) 0 , (b) 0.2 , (c) 0.4 , (d) 0.6 , (e) 0.8 , (f) 1 .

Table 1. Crystallographic Data and Atomic Coordinates of $\mathrm{Pb} 50 \%$ in the $\mathrm{Sr}-\mathrm{Pb} \mathrm{HAp}$ Sample from Rietveld Analysis

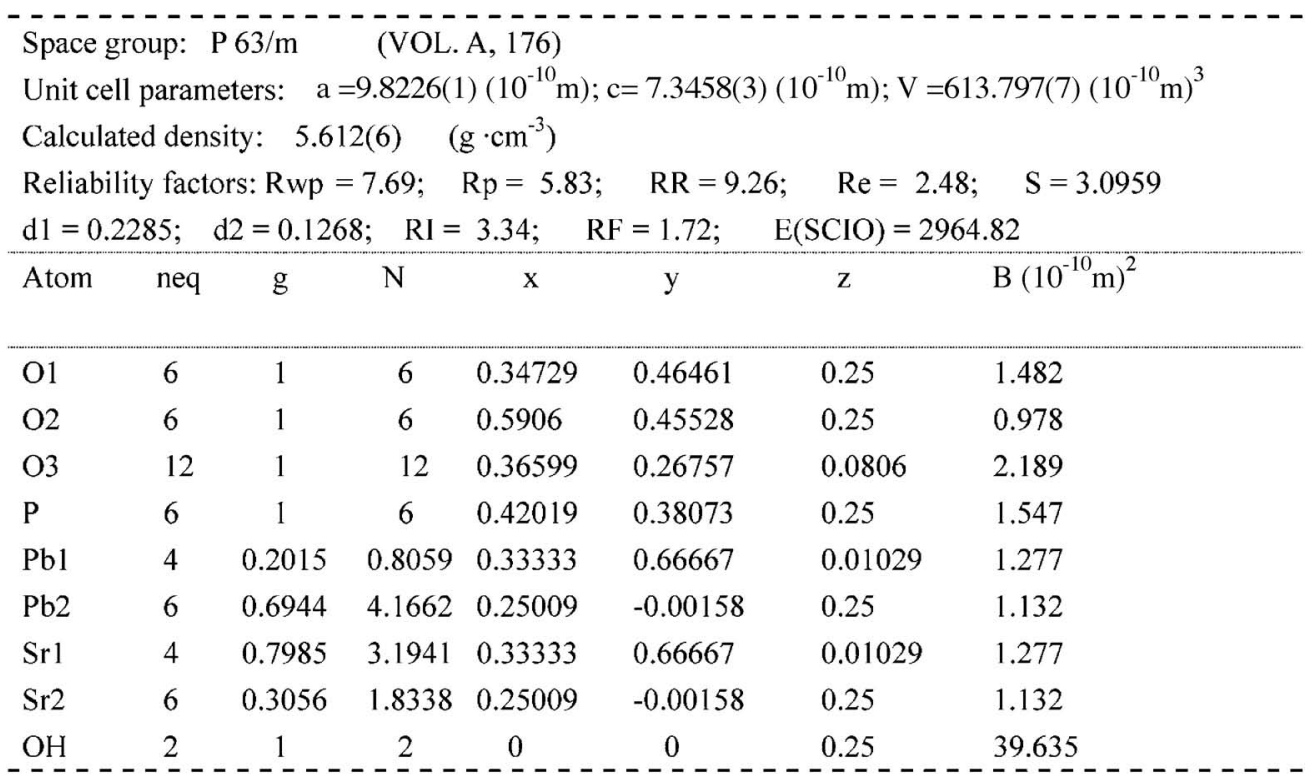

neq: number of equivalent points $\mathrm{g}$ : site occupancy factors

$\mathrm{N}$ : atom numbers per unit cell calculated from neq $* \mathrm{~g}$

$\mathrm{OH}$ : virtual atom consisted from $\mathrm{O}-1.0000$ and $\mathrm{H} 1.0000$

the $\mathrm{M}(1)$ and $\mathrm{M}(2)$ sites in the $\mathrm{Sr}-\mathrm{Pb} \mathrm{HAp}$ structure. It was found that $\mathrm{Pb}$ ions preferentially occupied $\mathrm{M}(2)$ sites in the solid solutions, and the amount increased with the increase of $\mathrm{Pb}$ content. The amount of $\mathrm{Pb}^{2+}$ ions in the $\mathrm{M}(2)$ sites increased slowly with the increase of the $\mathrm{Pb}$ content when the $\mathrm{Pb}$ content was higher than 0.6. However the occupancy of $\mathrm{Pb}^{2+}$ ions in the $\mathrm{M}(2)$ sites increased sharply when the $\mathrm{Pb}$ content is lower than 0.6 .

Many works ${ }^{6), 12), 19)-20)}$ have investigated the occupancy of metal ions in the site of apatite structure. All results showed that it seemed the bigger ions occupied the $\mathrm{M}(2)$ sites preferentially since in site $\mathrm{M}(2)$ the arrangement of the staggered equilateral triangles allows for the optimization of the packing of large ions, in contrast to the $M(1)$ site where the strict alignment in the columns causes a stronger repulsion. The results of this work are agreement with this point. In our former work of $\mathrm{Ca}-\mathrm{Cd}$ system, ${ }^{15)} \mathrm{Cd}$ ions have a slight tendency to preferentially occupy the $\mathrm{M}(2)$ sites even though the ionic radius of cadmium is smaller than that of calcium. The difference in ionic radius $\left(0.99 \times 10^{-10} \mathrm{~m}\right.$ for 6 -coordinate octahedral $\mathrm{Ca}(2), 0.97 \times 10^{-10} \mathrm{~m}$ for 6 -coordinate octahedral $\mathrm{Cd}(2)$ ) appears too small to give explanation. A possible 


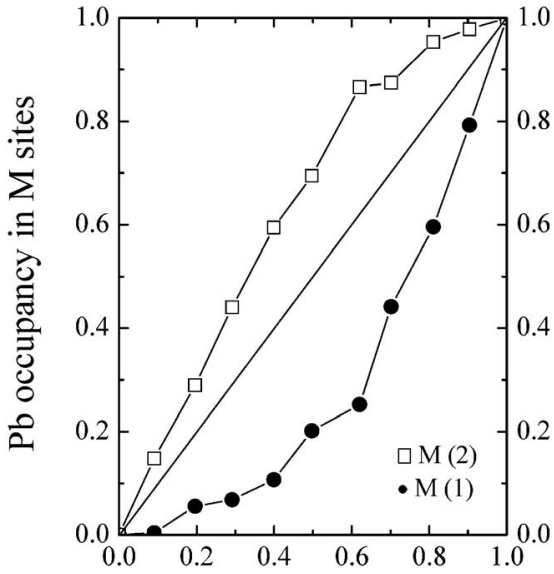

$\mathrm{Pb} /(\mathrm{Sr}+\mathrm{Pb})$ molar ratio

Fig. 5. Metal ion occupancy of the $\mathrm{Sr}-\mathrm{Pb} \mathrm{HAp}$ solid solutions prepared by $\mathrm{LTMM}$ against the $\mathrm{Pb} /(\mathrm{Sr}+\mathrm{Pb})$ molar ratio.

explanation for the preferential occupancy $\mathrm{Cd}^{2+}$ in the $\mathrm{M}(2)$ sites can be offered on the basis of elelctronegativities of the cations. Rajagopal et al. ${ }^{21)}$ showed that an increase in the electronegativity of the counter ion leads to an increase in the covalent character of the bond between the cation and the carboxyl group in metal arachidates. The electronegativity of the cadmium ion (1.7) is much bigger than that of calcium ion (1.0) so that $\mathrm{Cd}$ displays a greater tendency towards covalent interactions and directional bonding with hydroxyl group which locates at the channel surrounded by $\mathrm{Ca}^{2+}$ ions in $\mathrm{M}(2)$ sites. In other word, the $\mathrm{Cd}^{2+}$ ions with bigger electronegativity are easier to occupy $\mathrm{M}(2)$ sites than $\mathrm{Ca}^{2+}$ ions. In the $\mathrm{Sr}-\mathrm{Pb}$ HAp solid solutions, the ionic radius for 6-coordinate octahedral $\mathrm{Pb}(2)$ is $1.20 \times 10^{-10} \mathrm{~m}$, are bigger than that for 6-coordinate octahedral $\operatorname{Sr}(2)$ which is $1.13 \times 10^{-10} \mathrm{~m}$. The electronegativity of the lead ion (1.8) is also much larger than that of strontium ion (1.0). Therefore $\mathrm{Pb}^{2+}$ ions preferentially occupy the $\mathrm{M}(2)$ sites in the whole composition range of $\mathrm{Sr}-\mathrm{Pb} \mathrm{HAp}$ solid solutions.

We tried to explain the variation of the morphology as follows. Firstly, the solubility of $\mathrm{Pb}$ hydroxyapatite should be more than Sr hydroxyapatite so that the larger particle can be grown. Secondly, it will be explained by the dissolution species. It is reported that apatite is dissolved in solution as clusters, but not as ions. The clusters are larger than ion species, and should have some structure related to apatite structure. When the content of $\mathrm{Pb}$ is more than 60 atom $\%$, the $\mathrm{M}(2)$ sites are almost occupied only by $\mathrm{Pb}$ ions. I think that the clusters with a structure in which $\mathrm{M}(2)$ sites are occupied by $\mathrm{Pb}$ ions, have high solubility under hydrothermal conditions. The obvious change of morphology of the $\mathrm{Sr}-\mathrm{Pb} \mathrm{HAp}$ was observed around 70 atom $\% \mathrm{~Pb}$.

\section{Conclusions}

The solid solutions in the system of $\mathrm{Sr}-\mathrm{Pb} \mathrm{HAp}, \mathrm{Pb}_{x} \mathrm{Sr}_{1-x}$ HAp $(x=0-1)$, were successfully synthesized by LTMM at $160^{\circ} \mathrm{C}$ for $12 \mathrm{~h}$ under hydrothermal conditions. The morphology, growth mechanism, and the lattice constant of the solid solutions were investigated. The site of the metal ions in the solid solutions was also analyzed by the Rietveld method. The morphology of the samples with lower than $0.6 \mathrm{~Pb}$ content was rod-like. The smaller rod crystals coexisted with the larger bulky crystals in the solid solutions with $\mathrm{Pb}$ content from 0.6 to 0.9 . The morphology of lead hydroxyapatite crystal just was the larger bulk. The lattice constants of the solid solutions varied linearly with $\mathrm{Pb}$ contents. It was found that $\mathrm{Pb}$ ions in the solid solutions preferentially occupied $\mathrm{M}(2)$ site in the apatite structure.

Acknowledgments The authors would like to thank the financial support from Aeronautical Science Fund (No. 2006ZF52064) and the National 863 Foundation Program (No. 2007AA03Z104).

\section{References}

1) A. Yasukawa, T. Kunimoto, K. Kamiuchi, K. Kandori and T. Ishikawa, J. Mater. Chem., 9, 1825-1830 (1999).

2) Y. Matsumura, S. Sugiyama, H. Hayashi, N. Shigemota, K. Saitoh and J. B. Moffat, J. Molecular Catalysis, 92, 81-94 (1994).

3) K. Kandori, Y. Yamamoto, H. Saito and T. Ishikawa, Colloids and Surfaces A: Physicochem. Eng. Aspects. 80, 287-291 (1993).

4) S. Sugiyama, Y. Iguchi, H. Nishioka, T. Minami, T. Moriga, H. Hayashi and J. B. Moffat, J. Catal., 176, 25-34 (1998).

5) A. Hadrich, A. Lauti and T. Mhiri, J. Raman Spec., 32, 33-40 (2001).

6) B. Badraoui, A. Bigi, M. Debbabi, M. Gazzano, N. Roveri and R. Thouvenot, Eur. J. Inorg. Chem. 6, 1864-1870 (2002).

7) I. Khattech, Degree Thesis, Univeristé de Tunis, Tunisie (1996).

8) A. Bigi, E. Foresti, F. Marchetti, A. Ripamonti and N. Roveri, J. Chem. Soc., Dalton Trans., 1091-1093 (1984) .

9) M. Gazzano, PhD Thesis, University of Bologana, Bologna, Italy (1986).

10) A. Bigi, A. Ripamonti, S. Brückner, M. Gazzano, N. Roveri and S. A. Thomas, Acta Crystallogr., Sect. B, 45, 247 (1989).

11) A. Nounah, J. Szilagyi and J. L. Lacut, Ann. Chim. Fr., 15, 409 (1990).

12) B. Badraoui, A. Bigi, M. Debbabi, M. Gazzano, N. Roveri and R. Thouvenot, Eur. J. Inorg. Chem., 5, 1261-1267 (2001).

13) W. J. Dawson, Am. Ceram. Soc. Bull., 67, 1673-1678 (1998).

14) K. J. Zhu, K. Yanagisawa, A. Onda and K. Kajiyoshi, Soc. Solid State Chem., 177/12, 4379-4385 (2004).

15) K. J. Zhu, K. Yanagisawa, R. Shimanouchi, A. Onda and K. Kajiyoshi, J. Shaanxi University of Science \& Technology, 22 (5), 42-47 (2004).

16) K. J. Zhu, K. Yanagisawa, R. Shimanouchi, A. Onda and K. Kajiyoshi, J. Eur. Ceram. Soc., 26, Issues 4-5, 509-513 (2006).

17) K. J. Zhu, K. Yanagisawa, R. Shimanouchi, A. Onda and K. Kajiyoshi, Phosphorous Res. Bull., 17, 219-226 (2004).

18) Izumi F and Ikeda T, Mater. Sci., Forum, 321-324, 198-204 (2000).

19) U. Vincent, J. Jeanjean and M. Fedoroff, J. Solid State Chem., 108, 68-72 (1994).

20) B. Badraoui, R. Thouvenot, M. Debbabi and C. R. Hebd, Acad. Sc. Ser., 3, 107-112 (2000).

21) A. Rajagopal, A. Dhaanabalan, S. S. Major and S. K. Kulkarni, Applied Surface Science, 125, 178-186 (1998). 